\title{
Effect of new innovative restorative carbomised glass cement on intrapulpal temperature rise: an ex-vivo study
}

\section{Murat Selim BOTSALI ${ }^{(a)}$ \\ Uğur TOKAY(b) \\ Bilal OZMEN(c) \\ Murat CORTCU(c) \\ Alp Erdin KOYUTURK(c) \\ Firdevs KAHVECIOGLU(a)}

(a) Selçuk University, School of Dentistry, Department of Pediatric Dentistry, Konya, Turkey.

(b)Zirve University, School of Dentistry, Department of Pediatric Dentistry,

Gaziantep, Turkey.

(c) Ondokuz Mayıs University, School of Dentistry, Department of Pediatric Dentistry, Samsun, Turkey.
Declaration of Interests: The authors certify that they have no commercial or associative interest that represents a conflict of interest in connection with the manuscript.

Corresponding Author:

Uğur Tokay

E-mail: dtugurtokay@gmail.com

DOI: 10.1590/1807-3107BOR-2016.vol30.0067

Submitted: Nov 18, 2015

Accepted for publication: Feb 02, 2016

Last revision: Mar 23, 2016

\begin{abstract}
This study aimed to evaluate the temperature changes that occurred in the pulp chamber when using GCP Glass Carbomer Fill (GCP) and two different resin-modified glass-ionomer (RGI) restorative materials at different dentin thicknesses. A standardized Class I occlusal cavity with $1 \mathrm{~mm}$ or $2 \mathrm{~mm}$ dentin thickness was prepared in the extracted human molar teeth. RGI and GCP fills were placed in the cavities and cured with two different light-curing units. This study included a total of 120 samples, with 20 samples in each group. The pulp microcirculation method was used for measuring the intrapulpal temperature changes. Statistical analysis was performed using the two-way ANOVA and Tukey HSD multiple comparison tests. Statistically significant differences were observed between $1 \mathrm{~mm}$ and $2 \mathrm{~mm}$ dentin thicknesses $(\mathrm{p}<0.001$ ). The GCP groups (both $1 \mathrm{~mm}$ and $2 \mathrm{~mm}$ dentin thicknesses) exhibited higher temperatures than the other groups ( $<$ 0.001), and Fuji II LC and Photac Fil Quick Aplicap showed similar values $(p>0.05)$. The highest temperature changes were observed with $1 \mathrm{~mm}$ dentin thickness. While RGI materials in both dentin thicknesses did not cause temperature changes that were harmful to the pulp, GCP CarboLED LCU caused the highest intrapulpal temperature rise, and these values were borderline harmful to the dental pulp.
\end{abstract}

Keywords: Glass Ionomer Cements; Composite Resins; Dentin; Curing Lights, Dental.

\section{Introduction}

Dental pulp forms the core of the tooth and consists of living connective tissues that have a vulnerable and highly vascularized structure. Given the highly fragile nature of pulp tissue, any clinical restorative procedures that are performed in close proximity to the pulp cavity may impact the vitality of the pulp. One topic that is of particular concern is the heat that is generated during restorative operations. Intrapulpal temperature can be very easily affected by basic dental procedures, such as tooth preparation, exothermic setting, and other techniques used during restoration. ${ }^{1,2}$ However, anticipating and managing changes in this temperature can be quite complex as the extent of temperature variation is affected by several factors, including the type of light-curing unit (LCU) used, power density, exposure duration, distance between pulp and restorative materials, etc. ${ }^{3,4,5}$ Nevertheless, the heat produced by different dental procedures and/or materials used is undoubtedly one of the biggest sources of stress that can affect the vitality of 
the pulp. ${ }^{6}$ Zach and Cohen ${ }^{7}$ reported that an increase of just $5.5^{\circ} \mathrm{C}$ in the intrapulpal temperature for a duration of $10 \mathrm{~s}$ could result in serious histological changes in the pulp tissues, including protoplasm coagulation, expansion of the liquid present in the dentinal tubules, vascular injuries, and tissue necrosis. ${ }^{2}$

Glass carbomer fill (GCP) is a novel restorative filling material that incorporates nano-fluoride-hydroxyapatite particles. The manufacturer claims that GCP exhibits excellent clinical performance and is superior to many traditional and high-viscosity glass ionomer cement filling materials because of its nano-sized powder particles and fluoride-hydroxyapatite structure. ${ }^{8,9}$ They also claim that these nano-sized particles strengthen the material by increasing the total particle surface that is in contact with the glass-carbomer liquid. However, dentists must use a powerful light-curing source to set GCP, and this increases the temperature of the glass carbomer fill. ${ }^{10}$

This study aimed to evaluate the temperature changes that occurred in the pulp chamber when GCP was set using a light-curing source (GCP CarboLED thermo-cure lamp), and compare these temperature changes with those that occur with two different resin-modified glass-ionomer restorative materials and different dentin thicknesses. The null hypotheses of this study were as follows: (1) there would be no intrapulpal thermal changes when using GCP and the two resin modified glass ionomer cements, and (2) the different dentin thicknesses would have no effect on the intrapulpal thermal changes.

\section{Methodology}

This study used two freshly extracted human mandibular first molar teeth and 120 capsules of filling materials.

\section{Cavity preparation in the two molar teeth}

A water-cooled diamond disk was used to separate the root sections of the teeth, approximately $2 \mathrm{~mm}$ below the cement-enamel junction and perpendicular to the long axis. The remnants of the pulp were removed with a barbed broaches and an excavator.

To standardize restoration, the cusps of the teeth were removed with a diamond dental separating disc to create a flat occlusal surface. A Class I occlusal cavity with convex walls of $2 \mathrm{~mm}$ width and $3 \mathrm{~mm}$ length was prepared using a diamond fissure bur. A precision digital caliper (Mitutoyo, Tokyo, JAPAN) was used to ensure a dentine thickness of either $1 \mathrm{~mm}$ or $2 \mathrm{~mm}$ between the pulp chamber and the cavity floor. Pulpal blood microcirculation was simulated by using a flowable composite to attach the teeth to a polycarbonate plate designed by Savas et al. ${ }^{5}$ (Figure 1). A pipe that carried heated water $\left(37^{\circ} \mathrm{C}\right)$ was placed in one of the holes of the device, a drainage pipe was connected to the second hole, and a thermocouple device (Omega Engineering, Stamford, USA) was connected to the third hole. The thermocouple wire was linked to a data logger (XR440-M Pocket Logger; Pace Scientific, Mooresville, USA) and a computer, and this recorded the temperature inside the pulp chamber throughout the light-activated curing process. The water flow rate was set to a constant $0.026 \mathrm{~mL} / \mathrm{min}$ with the help of a digital infusion flow meter (SK-600II infusion pump, SK Medical, Shenzhen, China) attached to the system (Figure 1). ${ }^{5}$

\section{The experimental design}

The materials and LCUs used in the study are shown in Tables 1 and 2. A pilot study investigating the easy separation of restorative materials from the cavity using Vaseline found that it did not affect the temperature levels. Therefore, the prepared cavity was isolated with a thin layer of Vaseline prior to restoration. The restorative material was filled in the cavity according to the manufacturer's instructions, and the peak value of temperature in the pulp was measured during the light curing process. Thereafter, the restorative materials were removed from the cavity isolated with Vaseline. A probe was used to check the cavity for any remaining glass ionomer cement, and the same procedure was then repeated for the following groups (Figure 1):

a. Group 1A ( $\mathrm{n}=20): 1 \mathrm{~mm}$ dentin thickness, Fuji II LC, and VALO LED LCU.

b. Group 1B ( $\mathrm{n}=20): 2 \mathrm{~mm}$ dentin thickness, Fuji II LC, and the VALO LED LCU.

c. Group $2 A(n=20): 1 \mathrm{~mm}$ dentin thickness, GCP Glass Fill, and the GCP CarboLED thermo-cure lamp.

d. Group 2B ( $\mathrm{n}=20): 2 \mathrm{~mm}$ dentin thickness, GCP Glass Fill, and the GCP CarboLED thermo-cure lamp.

e. Group 3A $(n=20): 1 \mathrm{~mm}$ dentin thickness, Photac Fil Quick Aplicap, and the VALO LED LCU. 
Group 3B ( $\mathrm{n}=20): 2 \mathrm{~mm}$ dentin thickness, Photac Fil Quick Aplicap, and the VALO LED LCU.

The data logger was set at a sampling rate of 1 sample/ $2 \mathrm{~s}$ for the entire recording duration, extending from the commencement of light application until the temperature started to decrease (Figure 1). The collected data, in both tabular and graphical forms, were monitored in real time and transferred to the computer. Thereafter, the differences between the initial and highest temperature readings $(\Delta t)$ were calculated.

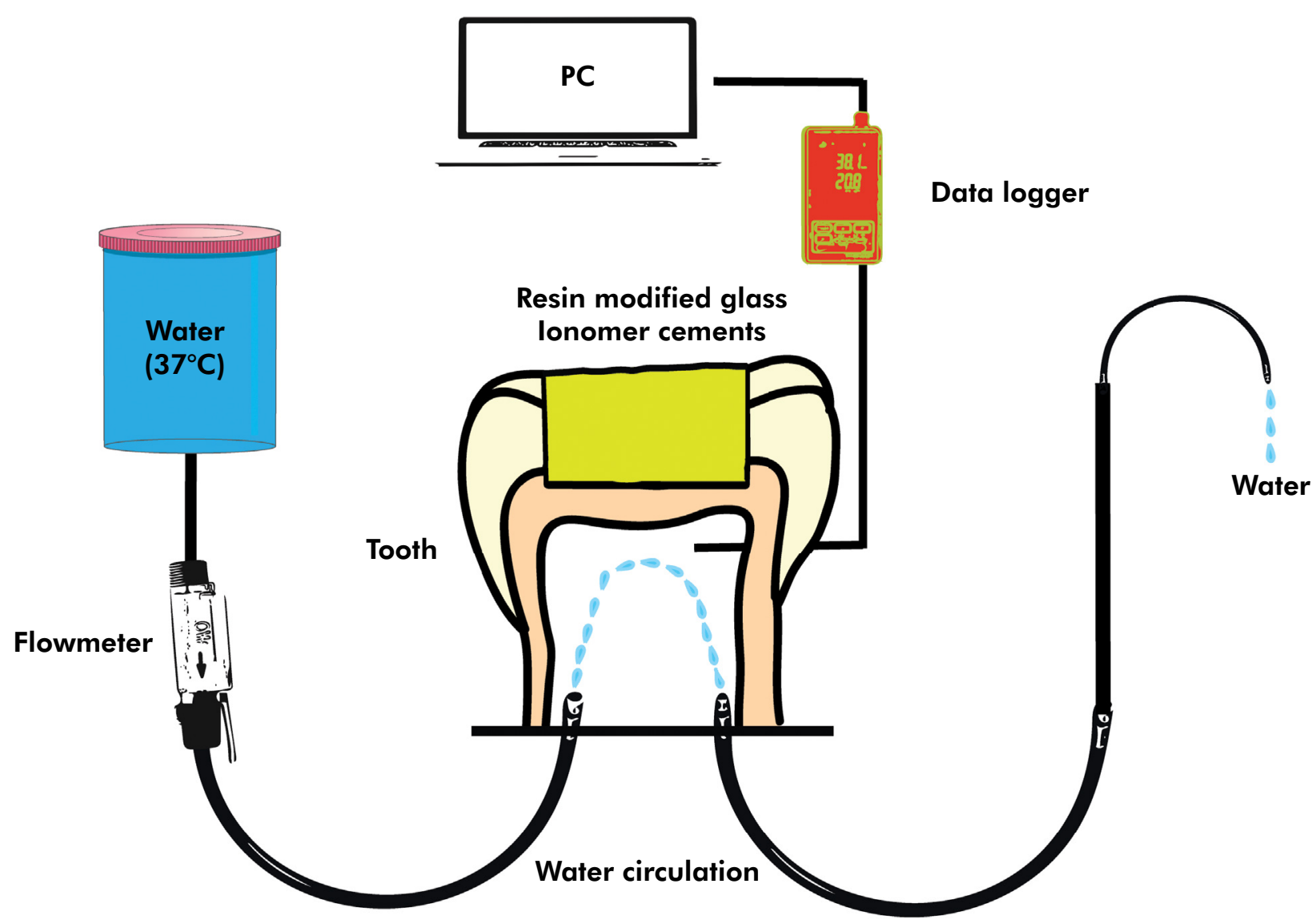

Figure 1. Schematic diagram of the measurement of intrapulpal temperature changes

Table 1. Materials used in this study.

\begin{tabular}{|c|c|c|c|}
\hline Materials & Manufacturer & Ingredients & Application techniques \\
\hline \multirow{2}{*}{$\begin{array}{l}\text { Fuji II LC } \\
\text { (Capsule) }\end{array}$} & \multirow{2}{*}{$\begin{array}{l}\text { GC Corp., Tokyo, } \\
\text { Japan }\end{array}$} & \multirow{2}{*}{$\begin{array}{l}\text { Distilled water, Polyacrylic acid, } \\
\text { 2- hydroxyethylmethacrylate, } \\
\text { Urethanedimethacrylate }\end{array}$} & $\begin{array}{l}\text { 1. Place mixed (10 } \mathrm{s} \text { in an amalgamator) Fuji II LC in } \\
\text { prepared cavity }\end{array}$ \\
\hline & & & 2. Light-cure for $20 \mathrm{~s}$ using VALO LED light-curing \\
\hline \multirow{3}{*}{ GCP Glass Fill } & \multirow{3}{*}{$\begin{array}{l}\text { GCP Dental, } \\
\text { Ridderkerk, } \\
\text { Netherlands }\end{array}$} & Fluoroaluminosilicate glass $>90 \%$ & $\begin{array}{l}\text { 1. Place mixed (15s in an amalgamator) GCP Glass Fill in } \\
\text { prepared cavity }\end{array}$ \\
\hline & & Apatitie $<6 \%$ & \\
\hline & & Polyacids $<4 \%$ & 2. Light-cure for ou s using GLP CarboLED thermo-cure \\
\hline \multirow[t]{2}{*}{$\begin{array}{l}\text { Photac-Fil } \\
\text { Quick Aplicap }\end{array}$} & \multirow[t]{2}{*}{$\begin{array}{l}\text { ESPE GmbH, Seefeld, } \\
\text { Germany }\end{array}$} & $\begin{array}{l}\text { Glass powder, surface modified } \\
\text { with 2-propenoic acid, } 2 \\
\text { methyl-.3-(trimethoxysilyl) }\end{array}$ & $\begin{array}{l}\text { 1. Place mixed ( } 10 \mathrm{~s} \text { in an amalgamator) Photac-Fil Quick } \\
\text { Aplicap in prepared cavity }\end{array}$ \\
\hline & & $\begin{array}{l}\text { propyl ester, bulk material, } \\
\text { N,N-Dimethylbenzocaine }\end{array}$ & 2. Light-cure for $20 \mathrm{~s}$ using VALO LED light-curing \\
\hline
\end{tabular}




\section{Statistical analysis}

The groups were compared using the two-way ANOVA, and the Levene test and Shapiro-Wilk test were used to test the results for equality of variances and the normality assumption, respectively $(p>0.05)$. Thereafter, the Tukey HSD multiple comparison test was applied to determine any further differences between the groups. The significance level was set at $\mathrm{p}<0.05$ for all the tests. All statistical analyses were performed using the SPSS program for Windows (V20, SPSS Inc., Chicago, USA).

\section{Results}

The results have been presented in Table 3 as mean, minimum, maximum, and standard deviation. Statistically significant differences in the recorded temperatures were observed between $1 \mathrm{~mm}$ and $2 \mathrm{~mm}$ dentin thicknesses $(p<0.001)$. High temperatures were recorded in the pulp chamber when GCP was used on teeth with both $1 \mathrm{~mm}$ and $2 \mathrm{~mm}$ dentin thicknesses ( $p<0.001)$. The GC Fuji II LC and the Photac Fil Quick Aplicap exhibited similar values $(\mathrm{p}>0.05)$ (Table 3).

A statistically significant difference was observed for same dentin thicknesses ( $p<0.001)$, and the highest measured temperature was observed in all groups with $1 \mathrm{~mm}$ dentin thickness (Table 3).

\section{Discussion}

An increase in temperature in the pulp chamber during restorative procedures can have a negative impact on the health of a vital pulp. Several factors can contribute to this increase, including cavity preparation procedures, bleaching of teeth, laser light applications, polishing of dental materials, and polymerization of light-cured materials. ${ }^{11,12}$ A polymerization-induced temperature increase can be caused by two main factors: 1) heat generated by the LCU during polymerization of materials, and 2) exothermic polymerization of the material. A number of additional factors, such as light intensity of the LCU, thickness of the remaining dentin, composition of the restorative materials, distance between the LCU and the material surface, position of LCU, and exposure time, ${ }^{13,14,15}$ can also affect the temperature of the pulp cavity during polymerization. This study aimed to determine the effects that the processes associated with the application of a new filling product, GCP, had on the intrapulpal temperature, and to assess whether different dentin thicknesses affected this in any way.

The first null hypothesis was rejected as intrapulpal thermal changes were observed. This was in accordance with the findings of a previous study. ${ }^{16}$ The second null hypothesis was accepted as the temperature changes observed in the pulp chamber during the restorative procedure varied according to the dentin thickness.

Table 2. Light curing unit used in this study.

\begin{tabular}{lccc}
\hline LCU & Manufacturer & Light Intensity & Curing time \\
\hline VALO LED light curing unit & Ultradent Products Inc., South Jordan, USA & $1,000 \mathrm{~mW} / \mathrm{cm}^{2}$ & $20 \mathrm{~s}$ \\
GCP CarboLED thermo-cure lamp & GCP Dental, Ridderkerk, Netherlands & $1,200 \mathrm{~mW} / \mathrm{cm}^{2}$ & $60 \mathrm{~s}$ \\
\hline
\end{tabular}

Table 3. Analytical and descriptive statistics of the intrapulpal temperature changes in all groups.

\begin{tabular}{|c|c|c|c|c|c|c|}
\hline \multirow{3}{*}{ Groups } & \multicolumn{6}{|c|}{ Dentin thickness $(n=120)$} \\
\hline & \multicolumn{3}{|c|}{$1 \mathrm{~mm}$} & \multicolumn{3}{|c|}{$2 \mathrm{~mm}$} \\
\hline & $n$ & Mean $\pm \mathrm{SD}\left({ }^{\circ} \mathrm{C}\right)$ & Min-Max & $\mathrm{n}$ & Mean $\pm \mathrm{SD}\left({ }^{\circ} \mathrm{C}\right)$ & Min-Max \\
\hline Fuji II LC & 20 & $3.84 \pm 0.47^{b}$ & $3.20-4.80$ & 20 & $0.50 \pm 0.08^{d}$ & $0.40-0.60$ \\
\hline GCP Glass Fill & 20 & $5.21 \pm 0.42^{a}$ & $4.50-6.20$ & 20 & $0.88 \pm 0.12^{c}$ & $0.70-1.10$ \\
\hline Photac Fil Quick Aplicap & 20 & $3.85 \pm 0.40^{b}$ & $6.20-4.70$ & 20 & $0.43 \pm 0.07^{d}$ & $0.30-0.50$ \\
\hline $\mathrm{p}$ values & \multicolumn{6}{|c|}{0.001} \\
\hline
\end{tabular}

SD: Standard Deviation. There is no statistically significant difference between same letters in same column $(p<0.05)$. 
Matalon et al. ${ }^{17}$ previously stated that no direct relationship between increases in temperature and the nature of the pulpal tissue damage had been observed, and thermal irritation may cause pulpal tissue damage or, at a minimum, changes to the pulpal tissue. An in vitro study conducted by Zach and Cohen ${ }^{7}$ in the 1960s using the teeth of monkeys was the first of its kind to observe the impact that thermal irritation has on pulp tissue. The researchers found that an intrapulpal temperature increase of $5.5^{\circ} \mathrm{C}$ for a 10 -s period resulted in histological changes to the pulp tissues. Although $15 \%$ of these cases culminated with irreversible pulpitis, the others remained vital. Additionally, Zach and Cohen ${ }^{7}$ reported that increasing the temperature further to $11.1^{\circ} \mathrm{C}$ for $10 \mathrm{~s}$ resulted in irreversible pulpitis in $70 \%$ of the cases.

Different types of equipment have been employed in previous studies evaluating the effects of an increase in temperature on the dental pulp. These include calorimeters, thermocouples, differential thermal analysis, and infrared cameras. ${ }^{18,19}$ In the current study, the thermocouple technique was used to measure temperature changes as it produces reliable and precise results. ${ }^{5,20,21}$ The pulp microcirculation helps regulate temperature when the pulp tissue is exposed to a thermal stimulus, and a number of previous studies have evaluated its role as a cooling agent in the thermal behavior of the dentin pulp complex. . $^{2021,22,23}$ In most in vitro studies, the treated teeth were placed in a tank containing still water at a temperature of $37^{\circ} \mathrm{C} .{ }^{22,23}$ In the current study, a pulpal circulation mechanism that simulated blood circulation in the pulp chamber using water flow was constructed to produce realistic results that were reflective of the biological processes.

Comparative studies have demonstrated that the thickness of the remaining dentin plays an important role in protecting the pulp chamber from temperature increases, ${ }^{24,25}$ and a number of studies have used one or more teeth to test the relationship between this thickness and pulp temperature. ${ }^{12,13,22,26}$ Studies examining multiple teeth have reported differences in tooth morphology, including enamel and dentine structure, and that the thickness of the dentin directly impacts the thermal conductivity of the tested teeth. ${ }^{19,25}$ Keeping this in mind, two mechanisms were prepared for different dentin thicknesses in the present study so as to standardize residual dentine thickness. Numerous samples were collected using this mechanism, and this ensured that any variables associated with enamel and dentine structure that could affect thermal conductivity and specific heat issues could be eliminated.

One of the disadvantages associated with the use of restorative materials that need to be polymerized using LCUs is the heat that is produced during the setting process. ${ }^{14} \mathrm{LCU}$ s with low energy outputs, such as Halogen and LED, cause lower temperature changes. ${ }^{18,27}$ A study conducted by Hannig and Bott ${ }^{28}$ showed that the highest temperature rise was observed with the Plasma Arc LCU $\left(7.8^{\circ} \mathrm{C}\right)$, followed by the Halogen LCU $\left(7.3^{\circ} \mathrm{C}\right)$ and the LED $\left(6.9^{\circ} \mathrm{C}\right) \mathrm{LCU}$. However, they suggested that the light intensity of an LCU is more important than the type as the long-term temperature peak may affect pulpal damage. Yazici et al. ${ }^{22}$ reported that the highest intrapulpal temperature was observed with the Halogen $\mathrm{LCU}\left(3.8^{\circ} \mathrm{C}\right)$, followed by the Plasma ArC $\left(2.4^{\circ} \mathrm{C}\right)$ and LED $\left(2.1^{\circ} \mathrm{C}\right)$ LCU. In the present study, the LED LCU was used for curing in Group 1 (the Fuji II LC group) and Group 3 (the Photac-Fil Quick Aplicap group). This unit increased the intrapulpal temperature from the commencement of the setting process by approximately $3.85^{\circ} \mathrm{C}$. The GCP CarboLED Lamp LCU was used to cure the restorations in Group 2 (those treated with GCP Glass Fill), and this LCU increased the intrapulpal temperature by approximately $5.21^{\circ} \mathrm{C}$. The manufacturers of the GCP Glass Carbomer Fill recommend that the CarboLED Lamp is used for the purposes of light-curing GCP and claim that this device will achieve the best results. However, the outputs of the current study indicate that the use of the CarboLED Lamp results in an exothermic setting reaction that raises the temperature of the pulp tissue in the tooth and, therefore, increases the risk of pulpal damage. Persistence of these temperature changes over a long period of time may lead to irreversible pulpal damage.

In the present study, the use of GCP Glass Carbomer in combination with the CarboLED Lamp resulted in the highest intrapulpal temperature changes $\left(5.21 \pm 0.42^{\circ} \mathrm{C}\right)$ in specimens with dentine thickness of $1 \mathrm{~mm}$. The temperature changes of specimens treated with Fuji II LC was $3.84 \pm 0.47^{\circ} \mathrm{C}$, and that of the Photac-Fil Quick Aplicap group was $3.84 \pm 0,40^{\circ} \mathrm{C}$. Furthermore, in specimens with dentine thickness of $2 \mathrm{~mm}$, the highest intrapulpal temperature changes were once again observed in the 
GCP Glass Carbomer Fill group $\left(0.99 \pm 0.66^{\circ} \mathrm{C}\right)$. However, according to a previous study, these temperaturechanges will not incur significant negative effects like irreversible pulpitis or pathological reactions in the pulp tissue.

An in vitro study conducted by Jacubinek et al. ${ }^{16}$ employing finite element analysis to investigate the effects of light intensity, curing mode, remaining dentin thickness, and the existence of a thermal barrier on intrapulpal temperature reported that the thickness of the remaining dentin affected the extent of intrapulpal temperature increase when high light intensity procedures are employed. They concluded that a thermal protection layer is required to cover the dental pulp. In the present study, a higher temperature increase was observed in specimens with a remaining dentin thickness of $1 \mathrm{~mm}$ compared to those with a dentine thickness of $2 \mathrm{~mm}$, and these results were in accordance with the previous study.

To the best of our knowledge, there are no other studies that have examined the intrapulpal temperature changes associated with resin-modified glass-ionomer cements and the newly developed GCP Carbomer Fill. Hence, this study predominantly focused on the thermal stimulation of the pulp when this material is used in combination with high light intensity procedures. The results suggest that the use of resin-modified glass-ionomer cements have no pathologic side effects on pulp. The highest temperature increase observed in this study was only $5.21 \pm 0.42^{\circ} \mathrm{C}$, and this value is borderline and below the critical temperature point of $5.6^{\circ} \mathrm{C}$ recommended by Zach and Cohen. ${ }^{7}$ As such, practitioners would need to employ a cavity protective liner when treating a deeper cavity that lies closer to the pulp, i.e., with a remaining dentin thickness of $<1 \mathrm{~mm}$.

\section{References}

1. Oztürk B, Uşümez A, Oztürk AN, Ozer F. In vitro assessment of temperature change in the pulp chamber during cavity preparation. J Prosthet Dent. 2004;91(5):436-40. doi:10.1016/j.prosdent.2004.02.022

2. Lieu C, Nguyen TM, Payant L. In vitro comparison of peak polymerization temperatures of 5 provisional restoration resins. J Can Dent Assoc. 2001;67(1):36-9.

3. Tokay U, Koyuturk AE, Aksoy A, Ozmen B. Do the monomers release from the composite resins after artificial aging? Microsc Res Tech. 2015;78(4):255-9. doi:10.1002/jemt.22468
Although a pulpal microcirculation mechanism was employed to simulate the biological pulpal situation, other aspects such as fluid motion in the dentinal tubules and the surrounding periodontal tissues of the teeth were not taken into consideration. These regulatory mechanisms may limit the intrapulpal temperature increase. However, clinicians should be aware of the potential thermal hazards associated with the use of LCUs. It must be emphasized that the results of this study cannot be directly extrapolated to in vivo situations. The present study was a laboratory experiment performed at room temperature, and the results may differ in intra-oral conditions.

\section{Conclusions}

Within the limitations of this study, the following conclusions were drawn:

a. All materials used in this study led to temperature changes within the pulp.

b. The temperature changes in the pulp depend on the remaining dentin thickness, material used, and LCU.

c. The use of GCP and the CarboLED Lamp LCU resulted in the highest intrapulpal temperature rise in teeth with $1 \mathrm{~mm}$ dentin thickness.

d. The lowest temperature rises were observed in specimens treated with resin modified glass ionomer cement.

\section{Acknowledgement}

The authors thank Prof. Dr. Soner Cankaya for the statistical analysis and GCP Dental, GC Corporation, 3M ESPE, and Mah-ya dental shop for their support during this study.
4. Murray PE, Smith AJ, Windsor LJ, Mjör IA. Remaining dentine thickness and human pulp responses. Int Endod J. 2003;36(1):3343. doi:10.1046/j.0143-2885.2003.00609.x

5. Savas S, Botsali MS, Kucukyilmaz E, Sari T. Evaluation of temperature changes in the pulp chamber during polymerization of light-cured pulp-capping materials by using a VALO LED light curing unit at different curing distances. Dent Mater J. 2014;33(6):764-9. doi:10.4012/dmj.2013-274 
6. Mjör IA, Ferrari M. Pulp-dentin biology in restorative dentistry. Part 6: reactions to restorative materials, tooth-restoration interfaces, and adhesive techniques. Quintessence Int. 2002;33(1):35-63.

7. Zach L, Cohen G. Pulp Response to Externally Applied Heat. Oral Surg Oral Med Oral Pathol. 1965;19(4):51530. doi:10.1016/0030-4220(65)90015-0

8. Koenraads H, Van der Kroon G, Frencken JE. Compressive strength of two newly developed glass-ionomer materials for use with the Atraumatic Restorative Treatment (ART) approach in class II cavities. Dent Mater. 2009;25(4):551-6. doi:10.1016/j.dental.2008.12.008

9. Chen X, Cuijpers V, Fan M, Frencken JE. Marginal leakage of two newer glass-ionomer-based sealant materials assessed using micro-CT. J Dent. 2010;38(9):731-5. doi:10.1016/j.jdent.2010.05.018

10. Kleverlaan CJ, van Duinen RN, Feilzer AJ. Mechanical properties of glass ionomer cements affected by curing methods. Dent Mater. 2004;20(1):45-50. doi:10.1016/S0109-5641(03)00067-8

11. Attrill DC, Davies RM, King TA, Dickinson MR, Blinkhorn AS. Thermal effects of the Er:YAG laser on a simulated dental pulp: a quantitative evaluation of the effects of a water spray. J Dent. 2004;32(1):35-40. doi:10.1016/S0300-5712(03)00137-4

12. Schneider LF, Consani S, Correr-Sobrinho L, Correr AB, Sinhoreti MA. Halogen and LED light curing of composite: temperature increase and Knoop hardness. Clin Oral Investig. 2006;10(1):66-71. doi:10.1007/s00784-005-0028-x

13. Uzel A, Buyukyilmaz T, Kayalioglu M, Uzel I. Temperature rise during orthodontic bonding with various light-curing units - an in vitro study. Angle Orthod. 2006;76(2):330-4.

14. Al-Qudah AA, Mitchell CA, Biagioni PA, Hussey DL. Effect of composite shade, increment thickness and curing light on temperature rise during photocuring. J Dent. 2007;35(3):238-45. doi:10.1016/j.jdent.2006.07.012

15. Asmussen E, Peutzfeldt A. Temperature rise induced by some light emitting diode and quartz-tungsten-halogen curing units. Eur J Oral Sci. 2005;113(1):96-8. doi:10.1111/j.1600-0722.2004.00181.x

16. Jakubinek MB, O'Neill C, Felix C, Price RB, White MA. Temperature excursions at the pulp-dentin junction during the curing of light-activated dental restorations. Dent Mater. 2008;24(11):1468-76. doi:10.1016/j.dental.2008.03.012

17. Matalon S, Slutzky H, Wassersprung N, Goldberg-Slutzky I, Ben-Amar A. Temperature rises beneath resin composite restorations during curing. Am J Dent. 2010;23(4):223-6.
18. Usumez A, Oztürk N. Temperature increase during resin cement polymerization under a ceramic restoration: effect of type of curing unit. Int J Prosthodont. 2004;17(2):200-4.

19. Guiraldo RD, Consani S, Lympius T, Schneider LFJ, Sinhoreti MAC, Correr-Sobrinho L. Influence of the light curing unit and thickness of residual dentin on generation of heat during composite photoactivation. J Oral Sci. 2008;50(2):137-42. doi:10.2334/josnusd.50.137

20. Ramoglu SI, Karamehmetoglu H, Sari T, Usumez S. Temperature rise caused in the pulp chamber under simulated intrapulpal microcirculation with different light-curing modes. Angle Orthod. 2015;85(3):381-5. doi:10.2319/030814-164.1

21. Sari T, Celik G, Usumez A. Temperature rise in pulp and gel during laser-activated bleaching: in vitro. Lasers Med Sci. 2015;30(2):577-82. doi:10.1007/s10103-013-1375-5

22. Yazici AR, Müftü A, Kugel G, Perry RD. Comparison of temperature changes in the pulp chamber induced by various light curing units, in vitro. Oper Dent. 2006;31(2):261-5. doi:10.2341/05-26

23. Michalakis K, Pissiotis A, Hirayama H, Kang K, Kafantaris N. Comparison of temperature increase in the pulp chamber during the polymerization of materials used for the direct fabrication of provisional restorations. J Prosthet Dent. 2006;96(6):418-23. doi:10.1016/j.prosdent.2006.10.005

24. Dogan A, Hubbezoglu I, Dogan OM, Bolayir G, Demir H. Temperature rise induced by various light curing units through human dentin. Dent Mater J. 2009;28(3):253-60. doi:10.4012/dmj.28.253

25. Secilmis A, Bulbul M, Sari T, Usumez A. Effects of different dentin thicknesses and air cooling on pulpal temperature rise during laser welding. Lasers Med Sci. 2013;28(1):167-70. doi:10.1007/s10103-012-1108-1

26. Carrasco TG, Carrasco-Guerisoli LD, Fröner IC. In vitro study of the pulp chamber temperature rise during light-activated bleaching. J Appl Oral Sci. 2008;16(5):355-9. doi:10.1590/S1678-77572008000500010

27. Oztürk B, Oztürk AN, Usumez A, Usumez S, Ozer F. Temperature rise during adhesive and resin composite polymerization with various light curing sources. Oper Dent. 2004;29(3):325-32.

28. Hannig M, Bott B. In-vitro pulp chamber temperature rise during composite resin polymerization with various light-curing sources. Dent Mater. 1999;15(4):275-81. doi:10.1016/S0109-5641(99)00047-0 